\title{
Atravessamentos de histórias de vida e percursos formativos de professores(as) na Educação Ambiental escolar do Distrito Federal/Brasil
}

\section{Crossings of life stories and formative paths of teachers in school Environmental Education in the Federal District/ Brazil}

\section{Cruces de historias de vida y caminos formativos de maestros en la Educación Ambiental escolar en el Distrito Federal/Brasil}

\begin{abstract}
Deise Barreto Dias ${ }^{1}$
Maria Rita Avanzi ${ }^{2}$

Resumo

Este artigo apresenta um recorte de uma pesquisa de doutorado que se encontra em andamento e visa compreender a inserção e desenvolvimento de Educação Ambiental na Educação Básica do Distrito Federal/Brasil, a partir de histórias de vida de sujeitos que influenciaram e influenciam nesse processo. As reflexões se inserem em um contexto mais amplo, que indaga sobre possíveis contribuições para a formação de outros(as) professores(as) que queiram atuar com EA em contexto escolar. Para desenvolver o trabalho escolhemos, por referencial teórico-metodológico, o método biográfico. Considerando os atravessamentos entre histórias de vida, percursos formativos desses sujeitos e o histórico da inserção e enraizamento da EA no Distrito Federal/Brasil foi possível perceber aspectos idiossincráticos e históricos da EA no contexto escolar, identificar momentos-charneira e construir contribuições para a Formação de Professores para atuar com EA.
\end{abstract}

Palavras-chave: História de vida. Educação Ambiental Escolar. Formação de Professores.

\begin{abstract}
This article presents an excerpt from a $\mathrm{PhD}$ research that is underway and aims to understand the insertion and development of Environmental Education in Basic Education in the Federal District/Brazil, based on the life stories of subjects who influenced and influence this process. The reflections are part of a broader context that asks about possible contributions to the training of other teachers who want to work with EE in a school context. To develop the work, we chose the biographical method by theoretical-methodological reference. Considering the crossings between life histories, the formative paths of these subjects and the history of the insertion and rooting of the Environmental Education in the Federal District/Brazil, it was possible to perceive idiosyncratic and historical aspects of the Environmental Education in the school context, identify hinge moments and build contributions to the teacher training to work with Environmental Education.
\end{abstract}

Keywords: Life history. School Environmental Education. Teacher Education.

\section{Resumen}

Este artículo presenta un extracto de una investigación de doctorado que está en curso y tiene como objetivo comprender la inserción y el desarrollo de la Educación Ambiental en la Educación Básica en el Distrito Federal/ Brasil, basada en las historias de vida de los sujetos que influyeron e influyen en este proceso. Las reflexiones son parte de un contexto más amplio, que pregunta sobre posibles contribuciones a la capacitación de otros maestros que quieran trabajar con EA en un contexto escolar. Para desarrollar el trabajo, elegimos el método biográfico por referencia teórico-metodológica. Teniendo em cuenta los cruces entre las historias de vida, los caminos formativos de estos sujetos y la historia de la inserción y el enraizamiento de la EA en Distrito

\footnotetext{
${ }^{1}$ Docente do Instituto Federal de Brasília e Doutoranda do Programa de Pós Graduação em Educação em Ciências da Universidade de Brasília. E-mail: deisebdias@gmail.com

${ }^{2}$ Professora Adjunta do Núcleo de Educação Científica do Instituto de Biologia e docente do Programa de Pós Graduação em Educação em Ciências da Universidade de Brasília. E-mail: mariarita@unb.br
} 
Federal/Brasil, fue posible percibir aspectos idiosincrásicos e históricos de la EA en el contexto escolar, identificar momentos clave y construir contribuciones a la formación docente para trabajar con EA.

Palabras-clave: Historia de vida. Educación ambiental escolar. Formación docente.

\section{Contextualizando a pesquisa}

Este artigo apresenta um recorte de uma pesquisa de doutorado que se encontra em andamento e busca trazer contribuições na interface entre os campos de Educação Ambiental (EA) e Formação de Professores(as) a partir de uma inquietação sobre a inserção e enraizamento da EA em contexto escolar. Entendemos que a inserção da EA nas escolas depende de diferentes vieses, tais como: políticas públicas, gestão escolar, projetos da escola articulados em seu Projeto Político Pedagógico, atuação docente, participação da comunidade escolar e diversos outros. O presente trabalho se atém à perspectiva do(a) docente, especialmente para seus processos formativos para atuar na inserção e enraizamento da EA em contexto escolar. Cabe destacar que entendemos que a formação desse sujeito para atuar com a EA na escola não resulta, apenas, da formação inicial em um curso de graduação, mas de todo percurso formativo que atravessa e é atravessado por sua história de vida.

Outro importante recorte é o território em que este trabalho está sendo desenvolvido, o Distrito Federal (DF). Esse recorte auxilia a situar nossas reflexões sobre como chega e se enraíza a EA na Educação Básica. Nesse sentido, intentamos compreender essa perspectiva por meio de três professoras que contribuíram e contribuem para esse processo, observando, precipuamente, como se dão alguns atravessamentos entre histórias de vida e percursos formativos desses sujeitos como histórico da inserção e enraizamento da EA no contexto escolar do DF. O sentido de atravessamento tratado neste trabalho não se pauta pelo simples movimento de ir de um lado a outro, contudo se baseia na ideia de cruzar e transpassar, um movimento que deixa marcas por onde passa. Nesse sentido, as histórias de vida e os percursos formativos são atravessados e atravessam o histórico da inserção e desenvolvimento da EA escolar no Brasil e no DF.

Diante do exposto, as perguntas de pesquisa que orientaram este trabalho são: a) Quais percursos de sua história de vida as professoras participantes da pesquisa consideram marcantes para sua formação como educadoras ambientais? b) Quais atravessamentos podemos identificar entre seu percurso formativo como educadoras ambientais e a inserção da EA em escolas de educação básica do DF? Essas duas primeiras perguntas intentam contribuir para um terceiro questionamento mais amplo, que é tratado parcialmente neste artigo, e será ampliado com o desenvolvimento da pesquisa de doutorado: c) Quais contribuições os percursos formativos desses sujeitos trazem para as reflexões a respeito da Formação de Professores(as) para atuar com EA em escolas?

O objetivo geral desta investigação é, portanto, compreender a inserção e desenvolvimento de EA na Educação Básica do DF, a partir de histórias de vida de sujeitos que influenciaram e influenciam nesse processo, situando as reflexões no contexto mais amplo da Formação de Professores(as) para atuar com EA no âmbito escolar.

Considerando o contexto em que se inserem o objetivo e o problema de investigação que emolduram esta pesquisa, pontuamos dois âmbitos de relevância deste trabalho: acadêmico e político. Para a importância acadêmica, levamos em conta que a Formação de Professores(as) e a EA são campos de conhecimento em ascensão. Nas últimas duas décadas tem sido notável o crescimento da produção acadêmica nesses campos, tal como demonstra André (2009), relativo à Formação de Professores, e Fracalanza e Amaral (2006), no que se refere à Educação Ambiental. 
Há, ainda, levantamentos que destacam o crescimento do interesse na interface entre os dois campos. Carvalho e Farias (2011) perceberam considerável proporção de trabalhos que versam sobre formação docente na produção científica em EA da Associação Nacional de Pós-Graduação e Pesquisa em Educação (ANPED), na Associação Nacional de Pesquisa em Ambiente e Sociedade (ANPPAS) e no Encontro de Pesquisa em EA (EPEA). Pato, Sá e Catalão (2009) observaram a Formação de Professores(as) como tema presente nas pesquisas no grupo de trabalho de EA nas reuniões anuais da ANPED, entre 2003 e 2007.

Por sua vez, Rink e Megid Neto (2009) apresentam os processos de Formação de Professores(as)/agentes em EA como tendência crescente nos artigos publicados nos anais dos quatro primeiros EPEAs. Valentin (2016) destaca a preocupação com a Formação de Professores(as)/educadores(as) ambientais a partir dos relatos do III até o VII EPEA do GDP de Pesquisas Formação de Educadores/Professores. Dessa forma, apontamos elementos que justificam a importância de um trabalho que se debruce sobre o percurso formativo de professores(as)/educadores(as) ambientais.

Além disso, entendemos que há uma relevância política em recuperar o histórico dos atores da EA e o que se construiu até o presente momento no DF, em especial, ao considerarmos os ataques que a EA tem recebido desde 2019 com o desmonte das políticas públicas. A comunidade acadêmica brasileira ligada ao campo da EA construiu uma nota para protestar contra as medidas do atual governo brasileiro e ressalta que, nos últimos trinta anos, as políticas do campo ambiental "vêm sendo construídas de forma consultiva e participativa junto com a sociedade e, em particular nessa área, com a comunidade de educadores ambientais brasileiros" (ANPED, 2019, s/p) $)^{3}$.

A atuação do atual governo rompe com esse teor democrático na composição das políticas e representa um retrocesso em relação às conquistas no campo socioambiental de modo geral, e da EA, em particular. O cenário está caracterizado pela extinção ou mudança da estrutura das instituições, o que impacta as políticas ambientais. Para exemplificar esse desmonte, ressaltamos a reestruturação do Ministério do Meio Ambiente, que, por meio do decreto 9672/2019, extinguiu o Departamento de Educação Ambiental, e a reestruturação do Ministério da Educação, com o Decreto 10.195/2019, do qual não consta a presença da Coordenadoria Geral de Educação Ambiental (CGEA) (BRASIL, 2019a, 2019b).

A atuação do Órgão Gestor - criado pela Política Nacional de Educação Ambiental (PNEA) ou Lei nº 9.795 de 1999 (BRASIL, 1999) - depende da articulação das pastas dessas instâncias que foram extintas. É atribuição desse órgão coordenar a PNEA e implementar "programas e projetos desenhados no âmbito do Programa Nacional de Educação Ambiental $(\text { ProNEA })^{4}$, inspirados no Tratado de Educação Ambiental para Sociedades Sustentáveis e Responsabilidade Global” (BRASIL, 2006, p. 3).

$\mathrm{Na}$ primeira seção, pretendemos expor duas perspectivas de estudos no campo da Formação de Professores(as). A primeira sobre professores(as) e a segunda com professores(as), a partir de uma contextualização histórica. Inserido nessa segunda perspectiva, abordamos, na seção dois deste artigo, o método biográfico, adotado como

\footnotetext{
${ }^{3}$ Fragmento do manifesto disponível em:

http://www.anped.org.br/sites/default/files/images/manifestoeducacaoambiental_janeiro2019.pdf

${ }^{4} \mathrm{O}$ ProNEA é um importante documento orientador e um marco referencial na implementação das políticas públicas de EA no Brasil. Apresenta diretrizes, princípios, visão, missão, objetivos, público e linhas de ação que orientam a EA no Brasil e se compromete com "o estímulo aos processos de mobilização, formação, participação e controle social das políticas públicas ambientais, em sinergia com as demais políticas federais, estaduais e municipais, desenvolvidas pelo Sistema Nacional de Meio Ambiente (Sisnama) (BRASIL, 2018). Teve seu primeiro lançamento em 2003 e encontra-se na sua quinta edição.
} 
referencial teórico metodológico dessa investigação. Em seguida, apresentamos os aspectos da história de vida e formação das três professoras que participaram da pesquisa. Por fim, buscamos anunciar algumas contribuições à interface dos campos da Educação Ambiental e Formação de Professores a partir de atravessamentos entre as histórias de vida, os percursos formativos e o histórico da EA escolar.

\section{Estudos sobre professores(as) $\mathrm{x}$ estudos com professores(as)}

Nóvoa (2013) situa temporalmente a predominância do que chamamos de estudos sobre professores (as) à segunda metade do século XX. Tais investigações consideraram a possibilidade de estudar o ensino para além da subjetividade do docente, de modo a se direcionar a uma ciência objetiva da educação. Esses estudos eram balizados por diversas vias e modelos racionalistas de ensino e se fundou como resposta possível diante do crescimento dos sistemas educativos. Nóvoa (2013, p. 14) reconhece esse reflexo como útil, porém simplista, pois "não é possível reduzir a vida escolar às dimensões racionais, nomeadamente porque uma grande parte dos atores educativos encara a convivialidade como um valor essencial e rejeita uma centração exclusiva nas aprendizagens académicas".

Galiazzi e Cupelli (2008) apontam que nessas pesquisas os(as) docentes são objetificados(as) pelo(a) pesquisador(a) que, por sua vez, se preocupa em apontar os erros e encaminhar soluções a essa comunidade que lhe é alheia. Logo, a produção de conhecimento se mostra desvinculada do contexto do(a) professor(a) e tem forte característica de regulação da prática docente.

Nóvoa (2013, p. 9) indica que "as utopias racionalistas não conseguiram pôr entre parênteses a especificidade irredutível da ação de cada professor, numa óbvia relação com suas características pessoais e com as suas vivências profissionais". Diante desse cenário, a perspectiva de estudos com docentes passa a ganhar território. Galiazzi e Cupelli (2008, p. 1) indicam que essa perspectiva valoriza a

[...] co-construção do conhecimento nas interações que se dá em uma comunidade interpretativa. Assim, o outro é elevado da condição de objeto à condição de sujeito, primando-se pela produção de um conhecimento-emancipação que tem a solidariedade como estado de saber.

Nóvoa (2013) sinaliza a publicação, em 1984, do livro “O professor é uma pessoa", de Ada Abraham, como um importante marco dessa virada por ser um trabalho que dá importância à vida dos(as) professores(as). Também, afirma que na década de 1980 aumentaram as produções que posicionam os(as) professores(as) no centro dos debates educativos e das problemáticas da investigação: "a literatura pedagógica foi invadida por obras e estudos sobre "a vida dos professores, as carreiras, os percursos profissionais, as biografias e autobiografias docentes ou o desenvolvimento pessoal dos professores". (NÓVOA, 2013, p. 15, grifos do autor).

Por mais que tenha sido notável a presença desses estudos nas últimas décadas, Bueno (2002) aponta que a abordagem biográfica já havia sido empregada nos anos 1920 e 1930 por sociólogos da Escola de Chicago. Nas décadas seguintes, em razão da predominância da pesquisa pautada pela objetividade e hegemonia da intencionalidade nomotética, a abordagem biográfica sofreu um colapso. Assim sendo, foi necessário um movimento que reconhecesse a legitimidade e o estatuto científico da abordagem biográfica enquanto método de investigação. O sociólogo Ferrarotti (2010), no texto Sobre a autonomia do método biográfico, versa acerca desse aspecto ao tratar da importância de se atribuir à subjetividade um valor de conhecimento, em contraponto à pesquisa positivista que a renegava. $\mathrm{O}$ autor 
também defende que a biografia pode evidenciar a ligação de uma história individual à história social, aspecto que tratamos mais adiante.

\section{Método biográfico como caminho para esta investigação}

Para desenvolver este trabalho, escolhemos como referencial teórico-metodológico o método biográfico. Isso porque esse método busca capturar a perspectiva dos sujeitos participantes da pesquisa e os sentidos que atribuem às suas experiências, considerando a indissociabilidade entre objeto e sujeito do conhecimento, uma vez que este está implicado no processo; além de valorizar a subjetividade como modo de produção de conhecimento (BUENO, 2002).

Outro aspecto a ser destacado sobre esse método é que ele considera a intersubjetividade como suporte do trabalho interpretativo e de construção de sentido para os relatos (JOSSO, 2010). E, ainda, procura estabelecer e revelar as relações entre história social e história individual (FERRAROTTI, 2010), o que nos auxilia fortemente no trabalho de busca de indícios sobre os atravessamentos entre aspectos idiossincráticos, que marcam os percursos de vida e formação dos sujeitos participantes da pesquisa, e o contexto mais amplo, histórico-social, enfrentando a questão sobre como a EA chegou e se enraizou no contexto escolar do DF. E, por último, por valorizar a escuta à voz docente, o método biográfico pode auxiliar na construção de identidades, na compreensão de como o sujeito se torna professor(a), o que possibilita integrar pesquisa e formação docente, considerando que o sujeito pode se formar à medida que se apropria das narrativas sobre o seu percurso. (NÓVOA, 2013)

Como instrumento de pesquisa, optamos pela técnica da entrevista semiestruturada pautada pelo método biográfico. Para identificar sujeitos potenciais para participação nesta investigação, desenvolvemos, como primeira fase, uma sondagem que buscava a identificação de instituições que participaram da inserção da EA em escolas do DF. Encontramos grande destaque para a Escola da Natureza, um centro de referência em atividades de EA da Secretaria de Estado de Educação do Distrito Federal (SEEDF) cuja importância é reconhecida no Plano Distrital de Educação Ambiental (DISTRITO FEDERAL, 2017).

[...] A Escola da Natureza tem se convertido ao longo dos anos num centro de referência em EA no Distrito Federal. Nascida como produto de uma demanda histórica de seu tempo, materializada pela ação de um coletivo de professores, tem tido uma função importante na história contemporânea da Educação de Brasília. [...] No decorrer dos anos, vem tentando afirmar-se dentro do cenário institucional e educativo tanto no âmbito de formação de educadores ambientais como também na ligação com escolas da rede pública que são atendidas por ela. (SORIA, 2012, p. 65)

Em seguida, buscamos estabelecer contato com a Escola da Natureza e conhecer sua história e seu trabalho. Também, realizamos observação participante na $10^{\mathrm{a}}$ edição do Encontro de Educadores Ambientais do Distrito Federal ${ }^{5}$, ocorrido em novembro de 2016, com o propósito de estabelecer trocas com os participantes, identificar sujeitos e conhecer projetos de EA desenvolvidos em escolas.

\footnotetext{
${ }^{5}$ Esse encontro propõe o compartilhamento de práticas pedagógicas por meio de diálogos, palestras e oficinas entre professores e especialistas para promover ações significativas sobre EA e é uma iniciativa da Secretaria de Estado de Educação do Distrito Federal, por meio da Gerência de Educação Ambiental e da Escola da Natureza, com instituições parceiras. Fonte: $<$ http://www.edgarlisboa.com.br/brasilia-faz-encontro-especifico-paraeducadores-ambientais/>. Acesso em 07/05/2020
} 
Essa fase de sondagem nos permitiu reconhecer professores(as) que marcaram o contexto da fundação e enraizamento do trabalho da Escola da Natureza e de docentes que possuem relevante atuação com projetos de EA em escolas do DF. Identificamos três professoras que representam diferentes gerações de educadoras ambientais do DF: Vera Catalão, Lêda Márcia Bevilacqua Bahdra e Luna Lambert. Essas professoras foram entrevistadas no primeiro semestre de 2018, a partir de um roteiro semiestruturado que as convidava a narrar sobre: sua trajetória profissional; a partir de quando perceberam seu envolvimento com a EA; o que acreditam que foi marcante na sua formação para atuar com a EA; o que consideram importante para a Formação de Professores (as) para que eles possam atuar com EA nas escolas; sobre possíveis indicações de outros sujeitos que atuam com EA em contexto escolar no DF. Outros questionamentos foram desenvolvidos ao longo da entrevista, de modo a estimular a narrativa de outros aspectos à luz dos objetivos desta pesquisa. As participantes assinaram um Termo de Consentimento Livre e Esclarecido, no qual optaram pela identificação de sua autoria nos relatos.

Por meio dos relatos cedidos nessa entrevista, buscamos as experiências no sentido Larrosiano: "a experiência é o que nos passa, o que nos acontece, o que nos toca" (LARROSA, 2015, p. 18). Assim, visamos voltar nosso olhar interpretativo para os relatos das entrevistas, buscando compreendê-las como experiência no sentido Larrosiano, a fim de captar sentidos formativos atribuídos pelos sujeitos da pesquisa a momentos de suas histórias de vida e os atravessamentos de seus percursos pessoais com um contexto mais amplo, de inserção e enraizamento da EA na educação básica do DF. Desse modo, intentamos perceber o que em sua subjetividade foi marcante e a relação disso com sua formação e com o contexto do histórico da EA no DF. Pretendemos, a seguir, detalhar a interpretação das entrevistas realizadas.

\section{História de vida e percurso formativo dos sujeitos de pesquisa: pistas de atravessamentos com o histórico da EA no DF}

Esta seção se destina a tratar os aspectos da história de vida e formação dos sujeitos que participaram da entrevista, trazendo uma apresentação do estudo interpretativo e fragmentos de seus relatos: a) Vera Catalão, psicóloga e professora universitária, considerada como pioneira na EA do DF, sendo uma das fundadoras da Escola da Natureza; b) Lêda Márcia Bevilacqua Bahdra, docente de língua portuguesa que atuou por dez anos à frente da direção da Escola da Natureza e c) Luna Lambert, professora de geografia, que se encontra à frente do Programa Escola na Rua, desenvolvido em uma das regiões administrativas do DF, São Sebastião.

Frisamos que esses nomes não são fictícios. As professoras autorizaram o uso de seus nomes reais na pesquisa, o que consideramos relevante, pois são coautoras do histórico da EA escolar no DF. Queremos, por meio de suas vozes, compreender como a EA se inseriu e enraizou no DF e trazer contribuições para a Formação de Professores(as) que queiram atuar com EA em contexto escolar.

Também, buscamos evidenciar, nesta seção, alguns fragmentos de relatos e momentos da história da EA no Brasil e DF evocados pelos depoimentos pessoais dos sujeitos, evidenciando a perspectiva do atravessamento.

\subsection{Vera Catalão: movimentos de contracultura e germinação da EA escolar no DF}


Vera trabalha com EA há muitos anos. Iniciou sua graduação em Psicologia na Universidade de Brasília (UnB) com dezessete anos, em 1968, com atuação no Centro Acadêmico de Psicologia. Em 1970, devido ao cenário político ditatorial no Brasil, trancou o curso e exilou-se na Inglaterra. Lá se envolveu com o Movimento Ecológico ou socioecológico.

Esse movimento referido por Vera se insere no contexto da contracultura que, segundo Carvalho (2001, p. 56), esteve historicamente ligado aos valores e comportamentos da geração jovem dos EUA, nos anos 1960 e 1970, mas transcenderam os limites da vida sociopolítica americana, marcando a "sociedade ocidental, fazendo adeptos e instituindo-se como um estilo alternativo de vida". Para essa autora, o movimento contracultural foi marcado por uma revolta "contra as instituições culturais dominantes de uma sociedade afluente, otimista e confiante que viveu um boom econômico pós-Segunda Guerra" e é nesse cenário que "a crítica ecológica ao progresso e ao capitalismo industrial nas décadas de 60 e 70 integra um espectro amplo e complexo de contravalores que se caracteriza pelo questionamento do status quo das sociedades desenvolvidas" (CARVALHO, 2001, p. 55, 57).

Nessas décadas, o ambientalismo no Brasil se pautava por um cunho conservacionista. Para compreender esse contexto, retomamos Carvalho (2001, p. 80) ao destacar o trecho de uma entrevista dada, em 1995, por Paulo Nogueira Neto: "Para nós, meio ambiente era conservação da natureza e ponto final. E permaneceu mais ou menos assim até os anos 70". Paulo Nogueira Neto foi um importante conservacionista na história do ambientalismo brasileiro, atuando como primeiro secretário da Secretaria Especial de Meio Ambiente (SEMA), criada pelo Governo Federal, em 1973, em resposta a "pressões internacionais para a introdução de políticas públicas ambientais na agenda de governo dos países" (BARBOSA, 2008, p. 8), após Conferência de Estocolmo, em 1972.

A SEMA teve importante atuação na criação das Estações Ecológicas (URBAN, 1998). Outra instituição, mais antiga e criada em 1967, dedicada à criação de unidades de conservação era o Instituto Brasileiro de Desenvolvimento Florestal (IBDF). Ainda assim, a gestão desses órgãos foi marcada pela falta de recursos materiais e humanos e conflitos internos.

Após dois anos na Inglaterra, Vera retornou à Brasília com a intenção de criar uma comunidade ecológica e participou da confecção do que considera o primeiro jornal ecológico do Brasil, Jornal Ordem do Universo, em 1974. Esse jornal teve apenas dez publicações e foi um dos materiais impressos que compôs o corpus de pesquisa de mestrado de Vieira (2015). Apesar de sua curta existência, a autora compreende que o Jornal Ordem de Universo (JOU) "foi um marco para a Nova Era no país, por ter sido um dos primeiros veículos a tratar exclusivamente deste movimento, traduzindo a sua essência" (VIEIRA, 2015, p. 14) e que "contribuiu para a divulgação do fenômeno da Nova Era no centro-oeste, sul e sudeste brasileiros" (VIEIRA, 2015, p. 13).

Vieira (2015, p. 22) afirma que a Nova Era floresceu na década de 1960, difundindose juntamente com os movimentos contraculturais. Uma de suas ações foi a composição de "comunidades alternativas, que rompiam com os valores capitalistas da época" e que almejavam uma cultura de paz em consonância com o pensamento das religiões orientais.

Essa autora destaca que o jornal se mantinha com a contribuição de assinantes e com espaço dedicado à publicidade, que, em sua maioria, comungavam com as ideias do periódico: "anúncios de terapeutas holísticos, tarólogos, restaurantes macrobióticos e vegetarianos, artistas, clínicas de medicina alternativa, livrarias, dentre outros" (VIEIRA, 2015 , p. 28). Também, ressalta que o JOU não se propunha a ser um modelo seguido com base na autoridade, mas apresentava "aportes apara que cada um consiga se autogovernar, e 
que volte o seu olhar para sentimentos como altruísmo, o equilíbrio e a positividade" (VIEIRA, 2015, p. 29)

Depois da sua atuação no JOU, Vera Catalão retornou à universidade, trazendo a questão ambiental como objeto de estudo acadêmico e envolvimento político como estudante universitária. Relacionando a vivência de Vera Catalão com o contexto apresentado por Carvalho (2001) e Morales (2007), podemos depreender que a professora faz parte da geração de fundadores do ambientalismo no DF.

Morales (2007, p. 27) identifica José Lutzemberger, Paulo Nogueira Neto e Aziz Ab Saber como representantes de uma geração fundadora de questões socioambientais fundamentais, pois foram exilados políticos que "retornaram ao Brasil, com vasta vivência em movimentos europeus que contribuíram com o movimento ambientalista brasileiro".

Carvalho (2001, p. 76) também trata, em sua pesquisa acerca da primeira faixa geracional na trajetória da Educação Ambiental no Brasil, pois são sujeitos "que participaram do contexto fundacional no qual a questão ambiental como debate e ação organizada emerge na esfera pública como tema de interesse e relevância para a sociedade".

Vera trabalhou durante alguns anos com Educação Patrimonial no arquivo público da Secretaria de Cultura do DF. Nos anos 1990, retomou questões sobre a EA durante o mestrado realizado na Faculdade de Educação (FE) da UnB.

Destacamos que, naquele momento histórico, o Brasil vivenciava grande efervescência da Educação Ambiental nas áreas governamental e não governamental, em virtude do que Czapski (1998) denomina processo da Rio-92, composto pelas fases preparatória e de realização do evento, e seus desdobramentos, tais como: a realização de eventos menores de EA, como o $1^{\circ}$ Encontro Nacional dos Centros de Educação Ambiental em dezembro de 1992; nesse mesmo ano, a criação da Rede Brasileira de Educação Ambiental; a retomada do projeto de lei da Política Nacional de Educação Ambiental na Câmara dos Deputados em 1993; o primeiro PRONEA, em 1994 (CZAPSKI, 1998)

No mestrado, Vera investigou experiências educativas de EA nas escolas públicas do DF. Uma dessas ações é o Projeto Ceilândia, considerado pioneiro pelo Plano Distrital de Educação Ambiental (DISTRITO FEDERAL, 2017). Segundo informações presentes na dissertação de Vera (CATALÃO, 1993), a região administrativa de Ceilândia foi criada em 1971, para remover famílias residentes em favelas das proximidades do centro de Brasília, o chamado Plano Piloto. Essas famílias foram deslocadas sem qualquer equipamento urbano que lhes desse condições favoráveis de moradia.

O Projeto de Educação Ambiental da Ceilândia foi proposto pela Secretaria de Educação e Cultura, em 1977, e "partia da extrema carência dessa cidade satélite propondo-se através da escola identificar, interpretar e transformar as condições ambientais da comunidade" (CATALÃO, 1993, p. 132). Outra experiência trazida na dissertação de Vera é o Projeto Núcleo do Jaburu, nascido em 1992, que tinha por estratégia "unir as informações sobre o ecossistema Cerrado com a proposta de uma atitude solidária e comunicativa com a natureza do lugar onde se fala" (CATALÃO, 1993, p. 169). O Palácio do Jaburu é a residência do vice-presidente do Brasil e o projeto desenvolvia atividades de EA com estudantes da rede pública do DF na orla do lago Paranoá e nos seus jardins. Suas intervenções "previam a divulgação de conhecimentos sobre flora e fauna do Cerrado por trilhas monitoradas, vídeos, debates e a distribuição do Gibi Cerradim" (DISTRITO FEDERAL, 2017, p. 8)

Em 1995, Vera passou a trabalhar com a implantação de EA no Projeto da escola Candanga, que se dispunha a "construir coletivamente uma escola pública, democrática e de qualidade, cuja expressão cultural esteja identificada com o espaço em que está inserida e com 
o povo candango que construiu e constrói esta Cidade" (DISTRITO FEDERAL, 2014a, p. 10). Já em 1996, a professora teve importante papel na criação da Escola da Natureza, que é considerada um dos frutos do Projeto Núcleo do Jaburu (DISTRITO FEDERAL, 2017).

De acordo com seu Projeto Político Pedagógico:

A Escola da Natureza é uma unidade escolar que integra a estrutura da Rede Pública de Ensino do Distrito Federal, está vinculada pedagógica e administrativamente à Coordenação Regional de Ensino, e aos demais órgãos competentes da Secretaria de Estado de Educação do Distrito Federal - SEEDF, responsáveis pela organização das políticas públicas relativas à Educação Ambiental - EA. Foi criada em 1996, pelo Conselho de Educação, sob a Resolução n ${ }^{\circ} 6020$ de 08 de agosto de 1997, publicado no DODF n 159 de 20 de agosto de 1997, com o objetivo de experimentar e propor metodologias para EA a fim de envolver e mobilizar a comunidade escolar da Rede Pública de Ensino por meio de atividades continuadas de Educação Ambiental (DISTRITO FEDERAL, 2018, p. 4).

Nesse espaço, esteve à frente de projetos transversais que traziam a água como matriz ecopedagógica e, posteriormente, esse se constituiu seu foco de pesquisa de doutorado, desenvolvida na França. Em seguida, passou a atuar na formação inicial - Licenciatura em Educação e Pedagogia - e na pós-graduação, da Universidade de Brasília. Em 2010 e 2011, desenvolveu sua pesquisa de pós-doutorado na FEUSP.

Atualmente, trabalha com pós-graduação na FE-UnB e tem um vínculo com a SEEDF, que a trouxe de volta para a Educação Patrimonial no Museu da Educação do Distrito Federal ou MUDE, um espaço de memória do passado em diálogo com a educação do presente. $\mathrm{O}$ MUDE tem como missão:

[...] preservar, salvaguardar e difundir a memória da educação pública do Distrito Federal, com vistas a fortalecer a identidade da escola e do professor e contribuir para a qualidade e renovação dos processos educativos, em beneficio da cidade e da educação brasiliense" (DISTRITO FEDERAL, 2014b, p. 11).

Institucionalmente, o Museu da Educação irá se configurar como uma fundação - a Fundação Museu da Educação do Distrito Federal (FAMUDE), a ser vinculada à SEEDF. Ainda não dispõe de sede própria e realiza seus trabalhos no Centro de Estudos Avançados Multidisciplinar (CEAM) da UnB. O Museu terá sua sede na Candangolândia, uma histórica região administrativa do DF por ter abrigado os construtores de Brasília, chamados candangos. Vera afirma que essa oportunidade a faz perceber as relações entre a EA e Educação Patrimonial.

No percurso de Vera, percebemos a importância da formação e da carreira acadêmica, ela identifica na infância a gestação de sua motivação e envolvimento com a EA, ou como ela mesma destaca:

O nascimento do meu sujeito ecológico é fora da universidade. Eu acho que a maior parte das pessoas... A minha paixão pela água veio do lugar onde vivi a minha infância que é Lençóis- Chapada Diamantina na Bahia. Ali a paixão pela água... E assim, o tipo de encantamento inicial surge ali. Depois a poesia teve uma contribuição muito forte na minha vida, eu escrevia ${ }^{6}$ (VC, 30/04/2018).

Vera afirma que, muito mais que a denúncia, é o encantamento que a toca, que a motiva, que a direciona para a questão ambiental, seja por seu envolvimento com movimentos sociais seja em seu percurso formativo e, posteriormente, em sua atuação profissional. O

${ }^{6}$ Os trechos das entrevistas são apresentados em itálico e com recuo para diferenciar das citações bibliográficas. Entre parênteses são apresentadas as iniciais da entrevistada, seguida da data em que foi concedida a entrevista. 
encantamento desperta em Vera o compromisso com os oprimidos. Ela pontua historicamente a posição na qual a natureza foi colocada, ou seja, como um ser oprimido, e traz a importância de reconhecer a natureza como um sujeito de direito. Para isso afirma a relevância de trabalharmos com educação de modo a atingir águas mais profundas.

\subsection{Lêda Márcia Bevilacqua Bahdra: ecologia profunda e enraizamento da EA escolar no DF}

Lêda é aposentada da SEEDF e trabalhou quinze anos na Escola da Natureza, sendo dez à frente da direção dessa escola. É especialista em educação ecológica e biocêntrica e tem, também, formação em biodança, que, como afirma, é a dança da vida.

[A biodança] tem a proposta também de trazer o conceito de Ecologia Profunda. E então eu inseri essa proposta na Escola da Natureza na formação de educadores ambientais (LBB, 29/03/2018).

Para Lêda, o envolvimento com a EA começou muito cedo, nos anos 1960 quando ainda tinha cinco anos de idade. Ela residia em Uberlândia/MG, em um bairro que tinha muito Cerrado em volta. Ela relata uma recordação marcante:

Eu saí correndo lá um dia, no meio do mato e desesperada dizendo que eu queria sentir cheiro de mato. Meus pais ficaram desesperados, foram atrás de mim, eu tinha só cinco anos. (...) Naquela época a gente não tinha nem noção, na década de 60, 70, do que era Educação Ambiental. O que era a questão. Não tinha essa preocupação ecológica como tem hoje (LBB, 29/03/2018).

Em seu depoimento, reforça que a relação com a natureza começa desde criança. $\mathrm{O}$ desconhecimento de Lêda quanto ao termo $E A$ é legítimo, uma vez que tal designação e suas bases são de origem internacional e vieram à tona a partir da Conferência de Estocolmo, em 1972.

Quanto ao contexto brasileiro, Silvia Czapski (1998) afirma que a EA era uma das atribuições da SEMA. Institucionalmente, apareceu em bases legais a partir da década de 80, tal como na Lei 6.902, de 1981:

[...] que estabeleceu novos tipos de áreas de preservação ambiental, entre as quais as Estações Ecológicas, destinadas à realização de pesquisas e à educação ambiental" e na Lei Federal $n^{\circ}$ 6.938/81, que institui a Política Nacional do Meio Ambiente "como um instrumento para ajudar a solucionar problemas ambientais (...) e já impõe que ela seja ofertada em todos os níveis de ensino" (CZAPSKI, 1998, p. 42).

Ainda na infância, Lêda gostava de frequentar fazendas, chácaras, ir à beira de rio para fazer acampamento. Durante a adolescência, assumiu que era mochileira, de ir dentro do mato. Sua formação universitária se deu em Letras e, posteriormente, atuou como professora de português nas escolas da SEDF. Em 1999, surgiu a proposta de Lêda trabalhar com projetos na Escola da Natureza. Ela aceitou e compôs a equipe até 2001. Trouxe, com detalhes, o contexto da criação da Escola, em 1996, ainda que não fizesse parte da equipe de fundadores.

Quem fundou a Escola da Natureza foi a professora Vera Catalão. Na época em 96, era o governo Cristovão e a Escola da Natureza era um stand, na verdade, de vendas de casa de madeira. (...) Aí foi desapropriado e o governo pediu, porque o espaço era público e estava sendo usado inadvertidamente pra fins privados. (...) $E$ então foi entregue para o GDF as casinhas. E a professora Vera estava na SEEDF, na secretaria de cultura e meio ambiente e ela viu ali essa oportunidade, né, então pediu pro governador pra poder essas casinhas irem pra SEEDF e ser um espaço de EA para receber alunos e professores (LBB, 29/03/2018). 
Saiu da Escola da Natureza por não se identificar, na época, com a gestão e com o trabalho que estava sendo desenvolvido, pois a preocupação da Escola se concentrava nas questões do lixo, da água, dos incêndios florestais, alimentação saudável e ecológica, trabalhadas por meio da participação pontual dos(as) alunos(as) em oficinas sobre esses temas. Lêda ressalta que não havia um retorno, uma continuidade do trabalho, o que acabou por desmotivá-la. Percebeu, ainda, que os servidores interessados em reformular e trazer uma nova proposta não estavam tendo espaço, o que levou parte da equipe a se desligar.

Seu retorno à Escola da Natureza ocorreu em 2004. Estava atuando como vice-diretora de outra escola, quando recebeu o convite da nova gestão, composta, entre outros, por Estevão Ribeiro Monti, que também fazia parte da equipe desligada da Escola da Natureza anteriormente. Sobre esse momento Lêda relata:

Então, foi muito importante esse momento foi o diferencial na escola. (...) Ele [Estevão] me convidou para fazer parte, para ser coordenadora e eu perderia a gratificação e lá eu iria como professora só, porque não tinha uma gratificação para coordenadora. Mas eu queria! Nossa, aí abriu um leque de possibilidades [...] de colocar em prática o que a gente já estava pensando (LBB, 29/03/2018).

Lêda ressaltou que, ainda em 2004, ocorreu o I Fórum de $\mathrm{EA}^{7}$ e, a partir dele, surgiu a ideia de formar um grupo de trabalho, o GTEA-DF. Mencionou, também, que esse grupo tinha de quinze a vinte pessoas e era composto por várias instituições: públicas, privadas, ONGs etc. A ideia desse grupo era construir um programa de EA para o DF em conjunto com todas essas instituições, de modo que a EA pudesse ser um conceito para todas as empresas, todas as instituições e não apenas uma proposta pontual. Lêda menciona que o GTEA-DF propôs à Escola da Natureza que oferecesse uma formação em nível geral, que não fosse só para professores(as).

A gente oferecia os cursos voltados para professores, mas com inscrições garantidas pra representantes de instituições públicas, ONG's... (...) E totalmente gratuito, ninguém pagaria nada. E aí foi uma riqueza muito grande porque a gente teve muitas pessoas envolvidas nesse processo e gente de todos os lugares (LBB, 29/03/2018).

O primeiro curso ocorreu entre 2004 a 2006 e Lêda atuou nessa proposta, ofertando o módulo de biodança. No último ano, também assumiu a direção da Escola da Natureza dando continuidade ao trabalho frente a essas demandas até o momento de sua aposentaria. Cabe destacar que, também em 2006, foi institucionalizada a Política de Educação Ambiental do Distrito Federal (PEA-DF) por meio da Lei $n^{\circ}$ 3.833, regulamentada em 2009 pelo Decreto Distrital $\mathrm{n}^{\circ}$ 31.129. Por meio dela foi criada a Comissão Interinstitucional de Educação Ambiental do DF (CIEA/DF), que visa "estabelecer canais de construção de diálogos para a implantação da PNEA (Lei n ${ }^{\circ}$ 9.795/99) e da PEA-DF (Lei no $3.833 / 2006$ ) e de promover a integração de ações." (DISTRITO FEDERAL, 2017, p. 9).

Ressaltamos que as CIEAs do Brasil correspondem a uma das formas de organização para debater e tomar decisões que, historicamente, contribuíram com a formulação de políticas públicas de EA no país, juntamente com o Órgão Gestor, seu comitê assessor, as Redes de Educação Ambiental e outros movimentos da sociedade civil.

[...] trabalhando em sintonia com a PNEA e o ProNEA, as CIEAs são protagonistas na elaboração e implementação, em seus respectivos estados, da Política e do

${ }^{7}$ Em 2003, foi realizado o I Fórum de Educadores Ambientais do DF, culminando na criação do $1^{\circ}$ Grupo de Trabalho de Educação Ambiental, que posteriormente deu origem à Comissão Interinstitucional de Educação Ambiental (CIEA/DF) (DISTRITO FEDERAL, 2017). 
Programa Estaduais de Educação Ambiental, de forma descentralizada, democrática e participativa. No mesmo sentido, têm a função de planejar, coordenar, acompanhar, avaliar e articular a execução das ações de educação ambiental nos estados, promovendo a ação coordenada da educação ambiental nas três esferas de governo e colaborando com a tarefa de transversalizar a temática ambiental nos governos e na sociedade (BRASIL, 2006, p. 14).

Reforçamos que toda essa estrutura está ameaçada frente ao atual desmonte do governo federal às políticas de EA, conforme já explicitado.

O Plano Distrital de Educação Ambiental constituiu uma das atribuições da CIEA/DF, por meio da PEA/DF. Esse documento foi elaborado de modo participativo e tem por objetivo [...] oferecer subsídios para a implementação da Política de Educação Ambiental no DF, com ênfase na conservação da sociobiodiversidade do Cerrado, na valorização do diálogo de saberes e na garantia dos direitos coletivos em direção à construção de sociedades sustentáveis, justas e solidárias (DISTRITO FEDERAL, 2017, p. 5).

Lêda recorda que, a partir de 2012, a Escola da Natureza passou a fornecer formação também para estudantes. A condição era que a Escola da Natureza contribuísse com a formação do(a) professor(a) e de seus/suas alunos(as). Nesse programa, Lêda tinha uma personagem, a Emerzina:

[...] era uma personagem que eu me vestia... Era uma sertaneja, que tinha chegado em Brasília, que tinha sido da década de 70... Aí ela chegava com uma mala, que tinha goiabada, tinha queijo... (risos) Doce de Buriti! E passava a mala assim para os alunos... E eles amavam isso! (...) Então era esse o meu papel no Programa Parque Escola (LBB, 29/03/2018).

Tanto para sua formação como para atuação com EA, Lêda crê que o contato com a natureza de uma forma mais profunda foi um fator marcante.

O que foi marcante foi esse contato com a natureza de uma forma mais profunda do que necessariamente reconhecer a natureza como um ente que está fora de nós. Então não é um ente fora, mas algo dentro... Então, assim, foi reconhecer que o ser humano é um meio ambiente em potencial... Que a relação com as pessoas proporciona um novo olhar pra natureza. Então isso foi determinante: reconhecer que a outra pessoa... Que o ser humano, ele está intrinsecamente relacionado à questão ambiental, ecológica... Que é mais do que ambiente. Porque quando a gente trata o termo ecológico a gente está abrangendo mais que ambiente. Ambiente ainda é restrito.... Ou ao meio biológico ou ao meio urbano. Quando a gente fala de ambiente... Mas quando a gente fala de ecológico a gente tá abrangendo tudo, abrangendo o planeta, na verdade (LBB, 29/03/2018).

\subsection{Luna Lambert: Permacultura nas ramificações da EA em escolas da periferia no DF}

Luna é geógrafa e começou a atuar em sala de aula em 2013. Afirma que está no início da carreira, mas nos apresenta os vários projetos em que tem atuado. Já trabalhou em Itapoã e, atualmente, está em São Sebastião, duas regiões administrativas da periferia do DF. Também está à frente do projeto Escola na Rua.

O Escola na Rua atua por diferentes caminhos. E ele é um programa de EA, embora eu não declare que ele seja um programa de EA... (...) mas ele é EA porque ele trabalha na ótica do como nós, cidadãos, podemos viver no nosso lugar.O que a gente tem que saber pra isso é como que a gente tem que proceder pra garantir (...) uma sustentabilidade (LL, 15/03/2018). 
Segundo página no Facebook $^{8}$, o Escola na Rua é uma iniciativa comunitária autônoma, que tem por objetivo levar o tema Educação para as ruas em prol da construção de ambientes de aprendizagem. Sua missão é criar articulações para melhorar a qualidade do ensino público, conscientizando sobre a importância da participação comunitária nas escolas. Duas escolas da região administrativa de São Sebastião/DF participam desse programa e Luna atua em uma delas.

Sobre seu envolvimento com a EA, Luna declara que sempre teve inclinação para o campo:

Olha eu acho que eu sempre tendi pra essa linha da EA, assim, até na adolescência as minhas buscas, os meus interesses, e de onde moro... (risos) Porque eu fui me encantando por essa coisa mais natureza. Eu sempre tive essa pegada da natureza. (...) A cidade sempre me incomodou, o calor, muita gente, barulho... Isso foi sempre algo muito perturbador... Desde criança. (...) E dentro da Educação eu comecei trabalhando com agricultores familiares. Comecei com essa pegada da Permacultura (LL, 15/03/2018).

O contato de Luna com a Permacultura revela-se como importante marca em sua história de vida, e atravessa sua formação e atuação profissionais.

Quando eu tive contato com a Permacultura, eu falei: nossa! Então todos os problemas que a gente vê aí da humanidade, eles têm solução! E as pessoas estão aplicando essas soluções, elas existem! A gente não precisa seguir esse caminho destruidor, né? Existem caminhos construtores, né? E criadores de vida (LL, 15/03/2018).

Esse contato ocorreu durante a graduação, quando viajou três meses por institutos de Permacultura no Brasil, onde trabalhou voluntariamente com bioconstrução e agrofloresta. Em 2011, já havia terminado bacharelado em Geografia na UnB e, para alcançar a dupla habilitação, faltavam duas disciplinas da licenciatura. Estava galgando o objetivo de viajar o Brasil em todos os centros de Permacultura e, por isso, chegou a pensar em não continuar a licenciatura. Contudo, motivos pessoais a levaram a reconsiderar:

Aí quando eu voltei pra Brasília para passar o Natal com a minha família, eu engravidei... Aí eu falei, ah cara... Aí eu vou terminar a licenciatura. Foi bem clara a coisa pra mim... (...) E hoje eu entendo que esse era meu caminho porque tudo na minha vida virou em função da educação (LL, 15/03/2018).

Luna iniciou sua atuação na docência como professora temporária na SEEDF na região administrativa de Itapoã e, ao mesmo tempo, desenvolvia seus estudos no mestrado. Inicialmente intencionava investigar e mapear comunidades tradicionais. Entretanto, estava para acontecer a IV Conferência Nacional Infanto-Juvenil pelo Meio Ambiente, organizada pela CGEA/MEC, e uma colega de trabalho, reconhecendo sua pegada com a natureza, a convidou para trabalhar com a Conferência. A partir disso, Luna teve contato com o documento do MEC intitulado Vamos cuidar do Brasil com escolas sustentáveis (BRASIL, 2012).

A Conferência Nacional Infanto-juvenil pelo Meio Ambiente caracteriza-se como [...] um processo de educação difusa que visa fortalecer a Educação Ambiental e a Educação para a Diversidade nos Sistemas de Ensino, propiciando atitude responsável e comprometida da comunidade escolar com as questões socioambientais locais e globais (BRASIL, 2006, p. 37).

${ }^{8}$ Endereço eletrônico: https://www.facebook.com/pg/escolanarua/about/?ref=page internal 
Sua primeira edição ocorreu em 2003, e envolveu dezesseis mil escolas em todo Brasil, mobilizando quase seis milhões de pessoas entre estudantes, professores e comunidades. A última conferência foi realizada em 2018, e contou com mais de nove mil escolas e 2,6 milhões de pessoas diretamente envolvidas. ${ }^{9}$ Essa conferência é uma das modalidades do programa Vamos Cuidar do Brasil com as Escolas, criado pelo MEC com a intenção de propiciar EA em contexto escolar. Esse programa "foi pensado como um círculo virtuoso contendo ações e práticas integradas, contínuas e transversais a todas as disciplinas. As ações se distribuem em quatro modalidades: difusa, presencial, educação a distância e ações estruturantes" (TRAJBER, SORRENTINO, 2007, p. 18).

O contato com a IV Conferência Infanto-Juvenil pelo Meio Ambiente fez Luna mudar a direção de sua pesquisa de mestrado. Passou a se debruçar sobre como o pensamento geográfico contribui para uma prática de EA crítica, utilizando a Conferência como elemento empírico. Sobre esse momento, Luna destaca:

E aí eu comecei todo o projeto lá da Conferência com a ideia do que é o Itapoã para mim, o que são problemas no Itapoã, o que acontece no Itapoã, vamos investigar o Itapoã pra ver como é que a gente enquanto escola consegue produzir soluções pras questões que a população do Itapoã enfrenta. Aí fizemos o projeto, participamos da Conferência e eu comecei a adensar o mundo teórico da EA, porque eu levei isso para o meu mestrado e comecei a adentrar essa arena, onde acontece todo um embate até (LL, 15/03/2018).

Com a pesquisa de mestrado (LAMBERT, 2015), Luna concluiu que a EA é um embate político. Além disso, durante a entrevista anunciou de forma marcante que trabalha na perspectiva da EA crítica.

Desde 2014, Luna é docente efetiva da SEEDF e afirma atuar com EA em uma perspectiva urbana. Também menciona que as inquietações advindas das reflexões de sua pesquisa de mestrado foram incorporadas em sua prática docente, pois trabalha a perspectiva da conexão com o lugar. Sobre o Escola na Rua, Luna expõe suas expectativas

É algo que eu preciso engrandecer! Vai ser um longo trabalho de conseguir fazer o Escola na Rua ser o que eu desejo que ele seja... o Escola na Rua ainda não chegou, tá longe de chegar no lugar que eu quero que ele chegue que é de fato ter um trabalho contínuo. Porque a EA, nessa ótica que eu trago, ela não é uma coisa assim... Ela não acontece de uma forma rapidinha... Ela não é uma intervenção, ela não é uma ação de plantar uma árvore ali... Ela transcende isso. Para que haja uma compreensão mais ampla do ambiente é necessário um trabalho muito continuo e esse é o grande desafio, eu acho... Como é que a gente consolida essa prática que, não vai ser permanente- porque nessa vida nada é permanente! Mas contínua a médio, longo prazo. Pra que o jovem saia dali realmente apropriado. Entendendo o mundo que ele vive, situado (...) Que é o que a gente trabalha na lógica do direito à cidade... Que é o direito de fazer na minha cidade aquilo que eu sonho pra minha cidade. Que cidade eu sonho? Então tem que mexer no sonho desse jovem! (LL, 15/03/2018).

\section{Atravessamentos e contribuições}

Nesta seção trazemos contribuições aos campos da Educação Ambiental e Formação de Professores(as) a partir de atravessamentos das entrevistas das professoras. São sentidos que construímos por meio do mergulho interpretativo à luz do referencial teórico-

${ }^{9}$ Conformes dados obtidos em http://conferenciainfanto.mec.gov.br/. Acesso: 03/03/20 
metodológico e dos objetivos desta investigação. São eles: a) aspectos idiossincráticos e históricos da EA no contexto escolar do DF; b) Momentos-charneira; c) Contribuições para a Formação de Professores (as) para atuar com EA.

\subsection{Aspectos idiossincráticos e históricos da EA no contexto escolar do DF}

Nos relatos, comparecem marcos históricos de movimentos sociais e as conquistas expressas em políticas públicas que influenciaram o percurso formativo e atuação das professoras, com isso revelam pistas acerca da inserção da EA no contexto escolar do DF, conforme procuramos evidenciar ao longo da seção anterior.

Sobre esse aspecto, Ferrarotti (2010, p. 45) afirma que somos a "reapropriação singular do universal social e histórico" do que nos rodeia, assim podemos conhecer o social a partir da especificidade irredutível de uma práxis individual. Nesse sentido, também contribui Josso (2010), quando afirma que:

[...] a história de vida permite evidenciar a intimidade de uma construção que valoriza uma concepção de identidade para si, simultaneamente singular e socioculturalmente marcada. Porém, é preciso não perder de vista que essa identidade para si não é uma individualidade sem ancoragens coletivas (familiar, de pertenças a grupo diversos com os quais todos e cada um tem uma história!) (JOSSO, 2010, p. 81).

Ainda que reconheçamos a importante correlação entre a história individual e social/coletiva, concordamos com Ferrarotti (2010) quando afirma que essa relação não é linear

[...] a relação estreita entre a história social e uma vida não é um determinismo mecânico. (...) $\mathrm{O}$ indivíduo não é um epifenômeno do social. (...) Mais do que refletir o social, apropria-se dele, mediatiza-o, filtra-o e volta a traduzi-lo, projetando-se numa outra dimensão, que é a dimensão psicológica da subjetividade (FERRAROTTI, 2010, p. 44).

Sobre esse aspecto, Josso (2010, p. 255) afirma: "sou um ser singular e um ser plural sociocultural; a minha singularidade utiliza modelos padronizados, mas não se identifica forçosamente com eles".

É nesse sentido que os relatos dos percursos formativos das professoras participantes da pesquisa nos permitem reconstruir momentos do histórico da EA no DF, marcado por movimentos ocorridos no Brasil e no mundo, desde a década de 1960. Para Vera, a fase política antidemocrática da história do Brasil torna o exílio obrigatório, o que a leva a entrar em contato com o movimento socioecológico. Esses acontecimentos marcaram sua história de vida e trouxeram grande contribuição ao contexto fundacional da EA no DF, tanto por sua atuação nos movimentos socioambientais, como por sua pesquisa de mestrado que investigou as experiências de EA no DF, com destaque aos pioneiros projetos de Ceilândia e do Núcleo do Jaburu. Anos após seu retorno, Vera liderou um dos frutos do projeto Jaburu, a Escola da Natureza, que representa um marco na EA escolar do DF. Vale ressaltar que sua paixão pela água, vinda desde a infância, inspirou seu trabalho nessa instituição e na pesquisa de doutorado que trata da água como matriz ecopedagógica.

Com relação a Lêda, é possível perceber que sua atuação na Escola da Natureza a levou à composição do GTEA-DF, coletivo que teve importante papel na proposição de curso de formação de educadores ambientais no DF. Esse grupo, posteriormente, deu origem à CIEA-DF, uma comissão respaldada por políticas públicas distrital e federal que teve como missão principal a construção do Plano Distrital de EA no DF. 
Quanto a Luna, é possível perceber como o trabalho com as atividades da IV Conferência Infanto-Juvenil pelo Meio Ambiente (também uma ação oriunda de política pública federal) influenciou sua pesquisa de mestrado e, posteriormente, sua atuação frente ao Programa Escola na Rua. Essa iniciativa integra o saber geográfico de sua formação inicial com referenciais da Permacultura e da Educação Ambiental crítica que acessou em seu percurso formativo, de modo a promover, junto aos jovens das periferias, uma reflexão com vistas à transformação de seu meio.

\subsection{Momentos-charneira e seu potencial formativo}

Retomamos Josso (2010) para tratar o conceito de momento charneira nas narrativas biográficas:

Tomada na sua globalidade, a narrativa articula períodos de existência que reúnem vários "fatos" considerados formadores. A articulação entre esses períodos efetua-se em torno de "momentos-charneira", designados como tal porque o sujeito escolheu sentiu-se obrigado a - uma reorientação na sua maneira de se comportar ou na sua maneira de pensar o seu meio ambiente ou de pensar em si por meio de novas atividades (JOSSO, 2010, p. 70).

São uma espécie de dobradiça entre duas etapas de vida, um divisor de águas. São acontecimentos que desencadeiam uma reorientação nos percursos de vida com reflexo na formação dos sujeitos.

É possível perceber nos relatos das professoras momentos de suas vidas em que essas reorientações ocorreram e foram importantes para a formação e/ou atuação em atravessamento com o percurso da inserção ou enraizamento de EA no DF. Podemos pensar, a partir desse conceito, nas seguintes situações: a) quando Vera entra em contato com o movimento ecológico na Inglaterra porque precisou sair do Brasil e isso, posteriormente, repercutiu no contexto fundacional da EA escolar no DF; b) quando Lêda decide voltar a atuar na Escola da Natureza, em 2004, mesmo perdendo a gratificação de sua atuação na escola anterior, pois identificou na gestão espaço para desenvolver uma proposta contínua de EA e pela satisfação profissional; c) quando a pesquisa de mestrado de Luna se reorienta a partir de uma demanda da atuação docente, em que trabalharia com as orientações da IV Conferência Nacional Infanto-juvenil pelo Meio Ambiente.

Para Josso (2010), a compreensão desses momentos-charneira é muito rica para o processo formativo. Neles, se confrontam a perspectiva pessoal e a relacional, o que oportuniza ao indivíduo compreender aspectos emotivos, afetivos e intelectuais, bem como estilos de vida e de convivencialidade em seu processo formativo. A consciência desses momentos pode apontar rotas e contribuições para formação de educadores (as) ambientais, uma contribuição do método biográfico como dispositivo de pesquisa e de formação.

\subsection{Contribuições para a Formação de Professores (as) para atuarem com EA}

Quando questionadas quanto às sugestões à formação docente, as entrevistadas manifestaram indicações afinadas com aspectos que marcaram seus percursos formativos e com suas referências teórico-metodológicas.

Vera indica que a educação de professores (as) tem que atingir águas mais profundas, o que nos remete à sua paixão pela água desde sua infância e ao seu campo de investigação que contempla a água como matriz ecopedagógica. O termo ecopedagogia foi cunhado pelo educador costarriquenho Francisco Gutiérrez, no início dos anos 1990. É uma perspectiva fundamentada por elementos do holismo, da complexidade e da pedagogia freireana, que 
busca "contribuir para a formação de novos valores para uma sociedade sustentável" (AVANZI, 2004, p. 36), a partir de princípios como cidadania planetária, cotidianidade e pedagogia da demanda.

Planetaridade e cidadania planetária são expressões que têm por proposta "construir a participação cidadã, considerando nosso pertencimento ao planeta Terra como uma única comunidade, de modo que as diferenças culturais, geográficas, raciais e outras sejam superadas" (AVANZI, 2004, p. 44). Já a consideração de ser a vida cotidiana o locus da mediação pedagógica pauta a coditianidade e dessa forma "a Ecopedagogia enfatiza as interconexões entre os seres humanos, os fenômenos naturais e os sociais", de modo que o processo pedagógico possa "desenvolver atitudes de abertura, interação solidária, subjetividade coletiva, sensibilidade, afetividade e espiritualidade" (AVANZI, 2004, p. 45). Por fim, a pedagogia da demanda visa a identificação e satisfação das necessidades que se apresentam no cotidiano do processo educativo por protagonistas da situação.

Afinada à Ecopedagogia, Vera afirma que a formação docente não pode se ater somente à dimensão da racionalidade científica, mas deve trazer, também, a dimensão do sensível, senão se torna estéril. Além disso, reconhece a importância de viver as múltiplas dimensões humanas numa visão transdisciplinar de modo a reconhecer a diversidade de saberes. Tece, por fim, uma crítica ao engessamento das universidades, indicando a dificuldade da interdisciplinaridade. Ela aponta que a estrutura universitária precisa ser mexida e que deve trabalhar mais forte na dimensão do currículo.

As contribuições trazidas por Lêda se afinam a uma referência teórica que marca seu depoimento, a Ecologia Profunda. Segundo Soria (2012), a Ecologia Profunda (EP) aponta para reflexões de ordem política, filosófica e espiritual e se constitui de conhecimentos inter e transdisciplinares. Esse autor recupera o histórico da EP, proposta em 1973 por Arne Naess, um filósofo norueguês. Naess questionou a ciência ecológica por estudar as relações das espécies com seu ambiente, mas não apresentar orientações acerca dos comportamentos e atitudes que os seres humanos deveriam adotar para enfrentar a crise ambiental. Por isso, construiu apontamentos que promoviam "pautas e práticas ecologicamente sustentáveis em oposição aos critérios socioeconômicos imperantes" (SORIA, 2012, p. 32), denominando-os por Ecologia Profunda (Deep Ecology).

Soria (2012, p. 28) também destaca que o termo ecologia teve, tem e terá muitas ressignificações, o que pode ser identificado pelos adjetivos a ele incluídos. Desse modo a EP pode ser considerada como uma ressignificação do termo que "estabelece uma ligação relacional entre o interno e o externo do ser humano, que tenta ir além da ecologia como ciência comum para abrir caminho para questionamentos de ordem filosófica e espiritual".

Além disso,

[...] a EP numa concepção ampla e abrangente, vai de dentro da nossa essência ao externo infinito, do micro ao macro, da matéria ao espírito, do material ao imaterial, do unidimensional ao multidimensional, observa uma série de relações que perpassam todos os elementos subjetivos, que vão desde as projeções psíquicas conscientes, consideradas como crenças, até a relação material do ser humano com todas as formas vivas que o rodeiam (SORIA, 2012, p. 36).

Lêda sugere que haja nos cursos de formação uma abordagem mais abrangente, que incorpore a Ecologia Profunda. Anuncia que quando esse referencial é tratado, é feito de forma superficial, somente a partir do conceito, sem incorporar a vivência.

Por fim, Luna considera que a Permacultura e a prática do estudo do meio são importantes ferramentas para um docente que queira atuar com EA nas escolas. Isso porque o sujeito compreenderá os agentes políticos e econômicos, a realidade da sociedade local, o 
contexto de sua formação e os tipos de problemas que acontecem em um dado lugar, aspectos que marcam um estudo do meio na perspectiva da EA crítica. A Permacultura entraria com propostas de solução já que, de acordo com Stumpf (2012, p. 3), ela envolve planejamento, implantação e manutenção de sistemas produtivos de modo que possam suprir as necessidades das populações humanas sem causar impactos ambientais e sociais negativos. Para isso busca desenvolver "um trabalho em conjunto com a natureza, integrando ideias das diversas áreas do conhecimento, das tradições e dos saberes populares, de forma adaptada a cada realidade".

Jacintho (2007, p. 40) identifica como um dos principais aspectos epistemológicos da Permacultura a

[...] importância dada à "observação do objeto" (área a ser projetada) por parte do projetista. Esta observação se refere às questões ambientais locais, aos aspectos socioculturais em meio à realidade específica, às possibilidades econômicas e ameaças externas ao loco do projeto.

Além desses aspectos, foi possível perceber, nas falas de Vera e Lêda, características que consideram importantes para um docente que queira trabalhar com EA. Vera ressalta a relevância de haver uma abertura pedagógica à dimensão do sensível. Diz que sem essa disposição não é possível fazer EA. Não destoante a esse aspecto, Lêda explana que o(a) docente disposto a trabalhar com EA tem uma visão mais holística, mais sistêmica. Conclui dizendo que "tem que ser aquele professor que saia mais da caixinha" (LBB, 29/03/2018).

Por fim, outra contribuição presente nas falas das professoras é a importância da arte na formação e atuação docentes. Vera destaca o trabalho de corporeidade no projeto Água Matriz Ecopedagógica, em que essa dimensão se manifesta por meio do ritmo, da arte popular e da poética da vida. A arte também norteia as atividades da Escola da Natureza, a atuação de Lêda na personagem Emerzina é um exemplo.

\section{Considerações finais}

A história de vida e percurso formativo dessas professoras nos permite identificar gérmens da EA escolar no DF, com destaque para o papel da Escola da Natureza na formação e na articulação de educadores(as) ambientais até a construção do Plano Distrital de EA, em 2017. É possível colher contribuições nos atravessamentos entre histórias pessoais e percursos da EA nacional e distrital, que trazem importantes elementos para a compreensão da inserção e enraizamento da EA na Educação Básica do DF.

Os atravessamentos aqui apresentados também nos implicam a revisitar o panorama histórico da EA, que revela um percurso de lutas e conquistas nos últimos trinta anos, os quais confluem com a história de vida de sujeitos que participaram da inserção e do enraizamento da EA na Educação Básica do DF. Nesse sentido, entendemos que as reflexões aqui desenvolvidas contribuem para a compreensão das dimensões subjetiva e histórico-social como complementares na formação de professores(as) e educadores(as) ambientais, reforçando o papel do método biográfico como dispositivo de pesquisa e formação.

A exemplo do que ocorre no Brasil, os elementos da EA no DF, identificados até o presente momento nesta pesquisa, resultam de uma heterogeneidade de perspectivas (Ecopedagogia, Ecologia Profunda, EA crítica, Permacultura) que trazem importantes contribuições para a Formação de Professores(as) que atuam com EA no contexto escolar.

\section{Referências}

ANDRÉ, M. A produção acadêmica sobre Formação de Professores: um estudo comparativo das 
dissertações e teses defendidas nos anos 1990 e 2000. Revista brasileira de pesquisa sobre formação docente, Belo Horizonte, v. 01, n. 01, p. 41-56, ago./dez. 2009.

ASSOCIAÇÃO NACIONAL DE PÓS-GRADUAÇÃO E PESQUISA EM Educação - ANPEd. 2019. Manifesto da Comunidade Acadêmica Brasileira da área de Educação Ambiental. Disponível em: 〈http://www.anped.org.br/sites/default/files/images/manifestoeducacaoambiental_janeiro2019.pdf〉. Acesso em: 30 abr. 2020.

AVANZI, M. R. Ecopedagogia. In: LAYRARGUES, P. P. (Coord.). Identidades da educação ambiental brasileira. Brasília: Ministério do Meio Ambiente, 2004. p. 35-49.

BARBOSA, L. C. Políticas públicas de educação ambiental numa sociedade de risco: tendências e desafios no Brasil. In: IV ENCONTRO NACIONAL DA ANPPAS. Anais... Brasília: ENANPPAS, 2008. p. 1-21. Disponível em: <http://portal.mec.gov.br/dmdocuments/publicacao11.pdf> Acesso em: 07 mai. 2020.

BRASIL. Casa Civil. Lei $n^{\circ}$ 9.795, de 27 de abril de 1999. Dispõe sobre a educação ambiental, institui a Política Nacional de Educação Ambiental e dá outras providências. Brasília: Casa Civil, 1999. Disponível em: <http://www.planalto.gov.br/ccivil_03/LEIS/L9795.htm〉. Acesso em: 20 abr. 2020.

BRASIL. Portfólio Órgão Gestor da Política Nacional de Educação Ambiental. Série Documentos Técnicos, $\mathrm{n}^{\circ}$ 7. Brasília: Ministério do Meio Ambiente (MMA) e Ministério da Educação (MEC). 2006.

BRASIL. Ministério da Educação. Vamos Cuidar do Brasil com Escolas Sustentáveis: educando-nos para pensar e agir em tempos de mudanças socioambientais globais. Brasília: Secretaria de Educação Continuada, Alfabetização, Diversidade e Inclusão (Secadi) - Ministério da Educação, 2012.

BRASIL. Ministério do Meio Ambiente-MMA. Ministério da Educação-MEC. Educação Ambiental por um Brasil sustentável: ProNEA, marcos legais e normativos. Brasília: MMA/MEC, 2018

BRASIL. Casa Civil. Decreto 9.672, de 2 de janeiro de 2019. Brasília: Casa Civil, 2019a. Aprova a Estrutura Regimental e o Quadro Demonstrativo dos Cargos em Comissão e das Funções de Confiança do Ministério do Meio Ambiente, remaneja cargos em comissão e funções de confiança e substitui cargos em comissão do Grupo-Direção e Assessoramento Superiores - DAS por Funções Comissionadas do Poder Executivo - FCPE. Disponível em: <http://www.planalto.gov.br/ccivil_03/_ato2019-2022/2019/decreto/D9672.htm>. Acesso em: 30 abr. 2020 .

BRASIL. Casa Civil. Decreto 10.195, de 30 de dezembro de 2019. Aprova a Estrutura Regimental e o Quadro Demonstrativo dos Cargos em Comissão e das Funções de Confiança do Ministério da Educação e remaneja e transforma cargos em comissão e funções de confiança. Brasília: Casa Civil, 2019b. Disponível em: <http://www.planalto.gov.br/ccivil_03/_ato2019-

2022/2019/Decreto/D10195.htm\#art9>. Acesso em: 30 abr. 2020.

BUENO, B. O. O método autobiográfico e os estudos com histórias de vida de professores: a questão da subjetividade. Educação e Pesquisa, São Paulo, v. 28, n.01, p. 11-30, 2002

CARVALHO, I. C. M. A invenção ecológica: narrativas e trajetórias da educação ambiental no Brasil. Porto Alegre: Editora Universidade/UFRGS, 2001. 
CARVALHO, I. C. M.; FARIAS, C. R. O. Um balanço da produção científica em EA de 2001 a 2009 (ANPED, ANPPAS E EPEA). Revista Brasileira de Educação, Rio de Janeiro, v.16, n. 46, p. 119134, jan./abr. 2011.

CATALÃO, V. M. L. Educação Ambiental e escola- retorno ao naturalismo ou senha para transformação? 194f. 1993. Dissertação (Mestrado em Educação) - Universidade de Brasília/ Faculdade de Educação, Brasília, 1993.

CZAPSKI, S. A. Implantação da educação ambiental no Brasil. Brasília: Ministério de Educação e do Desporto. 1998. 166 p.

DISTRITO FEDERAL. Secretaria de Estado de Educação. Projeto Cidade Escola Candanga. Brasília: SEEDF, 2014a.

DISTRITO FEDERAL. Plano Museológico. Brasília: Museu da educação do Distrito Federal, 2014b. Disponível em: <http://www.museudaeducacao.com.br/ctx-10/plano-museologico/>. Acesso em: 15 mar. 2020.

DISTRITO FEDERAL. Secretaria do Meio Ambiente. Plano Distrital de Educação Ambiental: PDEA. Brasília, SEMA, 2017.

DISTRITO FEDERAL. Secretaria de Estado de Educação. Projeto Político-Pedagógico Escola da Natureza. Brasília: SEEDF, 2018.

ERN. Escola na Rua. Página do Programa Escola na Rua @escolanarua no Facebook. Disponível em: <www.facebook.com/pg/escolanarua/about/?ref=page_internal> Acesso em: 07 mai. 2020.

FERRAROTTI, F. Sobre a autonomia do método biográfico. In: NÓVOA, A.; FINGER, M. (Orgs.). $O$ método (auto)biográfico e a formação. Natal: EDUFRN/São Paulo: Paulus, 2010. p. 33-57.

FRACALANZA, H.; AMARAL, I.A. do (coords.). A Educação Ambiental no Brasil: Análise da produção acadêmica (dissertações e teses) - $1^{a}$ FASE - Projeto de Pesquisa. Campinas:

FE/UNICAMP, 2006. Apoio CNPq.

GALIAZZI, M.C., CUPELLI, R. L. Narrando (re) existências: a produção de sentidos na constituição de professores educadores ambientais. In: REUNIÃO ANUAL DA ANPED, 31, 2008, Caxambu. Anais... Rio de Janeiro: Cadernos do GT 22 da Anped, 2008. p. 1-17. Disponível em: <http://31reuniao.anped.org.br/1trabalho/GT22-4559--Int.pdf>. Acesso em: 30 abr. 2020.

JACINTHO, C. R. S. A Agroecologia, a Permacultura e o Paradigma Ecológico na Extensão Rural: Uma Experiência no Assentamento Colônia I-Padre Bernardo-Goiás. 139 f. 2007. Dissertação (Mestrado em Desenvolvimento Sustentável) - Universidade de Brasília, Brasília, 2007.

JOSSO, M. C. Experiências de vida e formação. 2 ed. Natal: EdUFRN/São Paulo: Paulus, 2010.

LAMBERT, L. L. M. O estudo do meio na educação ambiental formal: contribuições da teoria crítica da Geografia. 115 f. 2015. Dissertação (Mestrado em Geografia). Universidade de Brasília, Brasília, 2015.

LARROSA, J. Tremores. Escritos sobre a Experiência. Belo Horizonte: Autêntica, 2015. 
LISBOA, E. Edgar Lisboa. 2014. Brasília faz encontro específico para educadores ambientais. Disponível em: <http://www.edgarlisboa.com.br/brasilia-faz-encontro-especifico-para-educadoresambientais/> Acesso em: 07 mai. 2020.

MORALES, A. G. M. A formação do profissional educador ambiental: reflexões, possibilidades e constatações no curso de especialização da UFPR. 233f. 2007. Tese (Doutorado em Meio Ambiente e Desenvolvimento)- Universidade Federal do Paraná, Curitiba, 2007.

NÓVOA, A. Os professores e as histórias da sua vida. In: NÓVOA, A. (Org.). A vida de professores. 2 ed. Porto: Porto Editora, 2013.

PATO, C.; SÁ, L.M.; CATALÃO, V.L. Mapeamento de tendências na produção acadêmica sobre educação ambiental. Educação em Revista, Belo Horizonte. v.25, n.02, p.213-233, 2009.

RINK, J.; MEGID NETO, J. Tendências dos artigos apresentados nos Encontros de Pesquisa em EA (EPEA). Educação em Revista, Belo Horizonte, v. 25, n. 3, p. 235-263, 2009. Disponível em: <http://www.scielo.br/pdf/edur/v25n3/12.pdf>. Acesso em: 30 abr. 2020.

SORIA, E. C. R. Ecologia Humana e Ecologia Profunda na Práxis de Educação Ambiental da Escola da Natureza. 152 f. 2012. Dissertação (Mestrado em Educação) - Universidade de Brasília/ PPGE/FE, Brasília, 2012.

STUMPF, B. O. Percepções de educadores sobre a Permacultura como estratégia de Educação Ambiental escolar. IX ANPED Sul. Seminário de pesquisa em Educação da região Sul. 2012.

TRAJBER R.; SORRENTINO M. Políticas de Educação Ambiental do Órgão Gestor. In: MELLO S. S.; TRAJBER R. (Orgs.) Vamos cuidar do Brasil: conceitos e práticas em educação ambiental na escola. Brasília: Ministério da Educação, Coordenação Geral de Educação Ambiental; Ministério do Meio Ambiente, Departamento de Educação Ambiental; UNESCO. Brasília. 2007. p. 13- 25

URBAN, T. Saudade do matão: relembrando a história da conservação da natureza no Brasil. Curitiba: editora UFPR; Fundação O Boticário de Proteção à Natureza; Fundação MacArthur. 1998.

VALENTIN, L. A formação continuada de professores em Educação ambiental na produção acadêmica (dissertações e teses). 161f. 2016. Tese (Doutorado em Educação) - Universidade Estadual Paulista, Instituto de Biociências de Rio Claro.

VIEIRA, K. M. S. Tempo e mito no discurso jornalístico: um estudo dos enunciados sobre a Nova Era. 97f. 2015. Dissertação (Mestrado Comunicação e Culturas Midiáticas) - Universidade Federal da Paraíba/CCHLA João Pessoa, 2015. 